\title{
VIABILIDADE DA APLICAÇÃO DA LOGÍSTICA REVERSA NO GERENCIAMENTO DOS RESÍDUOS DOS SERVIÇOS DE SAÚDE: UM ESTUDO DE CASO NO HOSPITAL $X$
}

\author{
Frank Pavan de Souza \\ Mestre em Engenharia Ambiental / ISECENSA \\ frankpavan@gmail.com \\ Manuella Guimarães Jacintho \\ Engenheira de Produção / ISECENSA \\ manuellajacintho@yahoo.com.br \\ Iris Thayná Peixoto Silva \\ Engenheira de Produção / ISECENSA \\ iris_peeixoto@hotmail.com \\ Karlayne Pessanha Gomes Viana \\ Engenheira de Produção / ISECENSA \\ karlaynepessanha@yahoo.com.br
}

Recebido: 03 de dezembro de 2012. Revisado: 25 de fevereiro de 2013. Aceito: 08 de março de 2013. Publicado online: 04 de setembro de 2013.

\section{RESUMO}

Os problemas ambientais gerados pelo homem são decorrentes do uso incompleto, ineficiente e ineficaz dos recursos naturais. Contudo, atualmente nota-se uma maior preocupação com os bens ambientais e com a destinação dada aos resíduos gerados pelos diferentes segmentos. Dentre esses resíduos, um grupo dos que mais preocupam são os gerados pelos serviços de saúde, devido à sua ação nociva ao ser humano e ao ambiente. $\mathrm{O}$ gerenciamento destes resíduos é uma alternativa encontrada para amenizar os impactos ambientais negativos que estes causam. Este trabalho tem como objetivo verificar e identificar os Resíduos de Serviços de Saúde do Hospital X que são passíveis de aplicação da Logística Reversa. A pesquisa foi aplicada no Hospital X, localizado no município de Campos dos Goytacazes, estado do Rio de Janeiro. Para o desenvolvimento da pesquisa foram realizadas atividades de campo e entrevistas com os principais responsáveis pelo plano de gerenciamento de resíduos do hospital. O trabalho em campo permitiu que se comparasse a forma de gerenciamento dos resíduos proposta pelo plano, com o que de fato é realizado pelo hospital. Ao final, percebeu-se que mesmo com as limitações da aplicação dos conceitos de Logística Reversa em grande parte dos rejeitos, é possível que sejam adotadas novas formas de gerenciamento dos resíduos da classe $\mathrm{D}$, possibilitando o retorno dos produtos ao ciclo produtivo. Com isso, demonstra-se que é possível que a Logística Reversa seja adotada como uma nova proposta de produção e consumo sustentáveis.

Palavras-Chave: Resíduos de Serviços de Saúde. Gestão ambiental. Logística Reversa. 


\begin{abstract}
Environmental problems created by people are due to the incomplete, inefficient, and ineffective use of the natural resources. However, today we can see the people more worried about environmental goods allocation given to waste created by the different segment. Among these wastes, a group of greatest concern is the one created by the healthy service due to its harmful effects to human and environment. The management of this waste is an alternative found to mitigate the negative environmental impacts caused by them. This work has as the goal to check and to identify the wastes of Health Services X Hospital that are capable of implementing Reverse logistics. The research was applied in the $\mathrm{X}$ hospital, located in Campos dos Goytacazes town, in the state of Rio de Janeiro. For the research development were realized field activity and interviews with primarily responsible for the waste management plan of the hospital. The fieldwork allowed comparing the form of waste management proposed by the plan, with what is actually done by the hospital. At the end it was noticed that even with the limitations of the application of the concepts of Reverse Logistics in most tailings, it is possible that new ways are adopted waste management D class, enabling the return of the products to the productive cycle. So it is possible that the reverse logistic can be adopted as a production proposal and sustainable consumption.
\end{abstract}

Key-Words: Waste Health; Environmental Management; Reverse Logistic.

\title{
1 INTRODUÇÃO
}

Ao longo do tempo, o mundo vem sofrendo mudanças estratégicas e estruturais. Os consumidores têm se tornado cada vez mais exigentes e, propiciando-se do avanço da tecnologia, as organizações vem tentando, a todo instante, suprir as necessidades de seus clientes. Para atender a essas necessidades de consumo de produtos e serviços, os recursos naturais acabam por ser transformados e, ao final de sua vida útil, são descartados de forma irregular.

No Brasil, embora o fato de que a problemática do meio ambiente venha sendo motivo de preocupação das nações em virtude das consequências das atividades humanas na qualidade de vida da população e ambiental, a Logística Reversa ainda é um tema pouco abordado. Somente após tramitar duas décadas no Congresso, finalmente foi promulgada a Lei $\mathrm{n}^{\circ} 12.305$, em 2 de agosto de 2010, que estabeleceu a obrigatoriedade da Logística Reversa no país, a qual deve envolver como atores governo, empresas e sociedade civil/Organizações Não-Governamentais (ONGs), representando um grande avanço, uma vez que institucionaliza a responsabilidade e a corresponsabilidade de cada participante da cadeia de suprimentos e resíduos.

As redes hospitalares não se excluem desse fato. Incessantemente, os serviços prestados pela área da saúde se tornam cada vez mais complexos e isso os responsabiliza por gerar cada vez mais resíduos de diferentes classificações e periculosidades.

Nessa perspectiva, os resíduos de serviços de saúde são os resíduos produzidos em hospitais, clínicas médicas e veterinárias, laboratórios de análises clínicas farmácias, centros de saúde, consultórios odontológicos, entre outros, (Philippi Jr. et al, 2004).

A fim de gerenciar de forma eficiente e eficaz os resíduos gerados pelos serviços de saúde, visando manter como pilar a segurança e a sustentabilidade, adota-se os conceitos de Logística Reversa. Em CLM 
(1993 p. 323) "Logística reversa é um amplo termo relacionado as habilidade e atividades envolvidas no gerenciamento de redução, movimentação e disposição de resíduos de produtos e embalagens...".

De acordo com a Lei 12.305/2010 que institui a Política Nacional de Resíduos Sólidos, "Logística Reversa é o instrumento de desenvolvimento econômico e social caracterizado por um conjunto de ações, procedimentos e meios destinados a viabilizar a coleta e a restituição dos resíduos sólidos ao setor empresarial, para reaproveitamento, em seu ciclo ou em outros ciclos produtivos, ou outra destinação final ambiental adequada."

A Logística Reversa baseia-se em quatro pilares de sustentação: a conscientização dos problemas ambientais; a sobre-lotação dos aterros; a escassez de matérias-primas; as políticas e a legislação ambiental. Segundo Barbieri e Dias (2002), a logística reversa deve ser concebida como um dos instrumentos de uma proposta de produção e consumo sustentáveis.

De acordo com o Artigo 225 da Constituição da República Federativa do Brasil 1988 "Todos têm direito ao meio ambiente ecologicamente equilibrado, bem de uso comum do povo e essencial à sadia qualidade de vida, impondo-se ao Poder Público e à coletividade o dever de defendê-lo e preservá-lo para as presentes e futuras gerações.”. Assim sendo, a Logística Reversa representa um grande avanço, uma vez que institucionaliza a responsabilidade de cada participante da cadeia de suprimentos e resíduos.

A ausência de um gerenciamento correto dos resíduos gerados no Brasil se desenvolve para um cenário cada vez mais grave. Dentre os resíduos gerados, destacam-se os resíduos de serviços de saúde, não pela sua quantidade gerada, mas pelo potencial de risco que apresentam à saúde humana e ao meio ambiente.

É de extrema importância que as organizações tenham conhecimento dos resíduos que geram independente do seu grau de periculosidade, tornando-se imprescindível a adoção de métodos efícazes que tenham por objetivo mitigar os impactos negativos, causados pelos resíduos lançados, ao meio ambiente.

A utilização dos conceitos de Logística Reversa visando aprimorar o gerenciamento destes resíduos gera incontestáveis benefícios ambientais. Assim sendo, adota-se canais de distribuição reversos devidamente estruturados e organizados, que possibilitem a minimização da geração, a partir de uma segregação eficiente, bem como métodos de tratamento que procuram reduzir o volume de resíduos a serem depositados no solo e expostos à comunidade.

Neste sentido, este trabalho tem como objetivo verificar e identificar os Resíduos de Serviços de Saúde do Hospital X que são passíveis de aplicação da Logística reversa.

\section{MATERIAL E MÉTODOS}

Inicialmente foi feito um estudo para conhecer o mais recente Programa de Gerenciamento de Resíduos de Serviço de Saúde do Hospital X (01/06/2012), elaborado pelo Serviço Especializado em Engenharia de Segurança e Medicina do Trabalho (SESMT). O plano aborda aspectos legais, tipos de resíduos gerados no hospital e caracterização, bem como quantidade e forma de descarte.

Baseado no plano existente e na pesquisa desenvolvida ao longo do trabalho foi elaborada uma entrevista semi-estruturada contendo 20 (vinte) perguntas que foram aplicadas aos principais responsáveis pelo desenvolvimento do plano (engenheiro de segurança do trabalho e técnico de segurança do trabalho). 
Ainda contribuindo com o estudo, uma segunda entrevista de mesmo tipo foi aplicada a enfermeira e professora Mirelli Silotti Mastelo que possui formação em Gestão Hospitalar e Gestão no Controle de Infecção Hospitalar e Tratamento de Feridas. Tal entrevista proporcionou uma visão prática de uma profissional experiente da área. $\mathrm{O}$ texto enfatiza apenas as respostas pertinentes ao conteúdo proposto, sendo assim, àquelas isoladas não estarão expressas na pesquisa.

Se tratando de uma pesquisa in loco, com a presença do técnico, foi realizado um trabalho de observação pelas dependências do hospital e ao abrigo externo dos resíduos até o momento de coleta pelas empresas contratadas. Assim foi possível identificar as áreas geradoras de resíduos de maior periculosidade, bem como a forma como cada uma descarta os resíduos de sua responsabilidade.

Esse contato permitiu que fossem obtidas informações que não foram expostas durante a entrevista e também, que fossem capturadas imagens (com a permissão da administração do hospital) que ilustram o tema.

Após recolher os dados, foi realizada uma análise comparativa entre o que consta no PGRSS e o que de fato é posto em prática no hospital. Ao final desta análise, foram apresentadas alternativas de descarte destes resíduos com base nos conceitos de logística reversa.

É importante salientar, que o Hospital não autorizou a divulgação do seu nome por motivos "particulares", por isso, foi denominado "Hospital X".

\section{ESTUDO DE CASO}

O estudo de caso foi realizado no Hospital X que tem como característica ser um Hospital Escola com aproximadamente 18 anos de atividade. Situa-se no município de Campos dos Goytacazes, estado do Rio de Janeiro. O Hospital conta com 124 leitos, 05 Salas de Cirurgia, Unidade de Terapia Intensiva com 07 leitos, Serviços de Clínicas Médica, Cirúrgica, Pediátrica, Ginecologia, Mastologia, Setores de Radiologia, Análises Clínicas, Anatomia Patológica, Hemodinâmica e Cirurgia Cardíaca, Neurocirurgia e Oftalmologia.

O presente plano de gerenciamento de resíduo de serviços de saúde do Hospital X é constituído de procedimentos de gestão, planejados e implementados tendo como respaldo bases científicas e técnicas, normativas e legais, e tem como objetivo diminuir a produção dos resíduos, bem como fazer um encaminhamento seguro, de maneira eficiente, almejando a proteção dos colaboradores, a preservação da saúde publica dos meios naturais e ambiente. Esse plano é baseado no Regulamento Técnico para o Gerenciamento de Resíduos de Serviços de Saúde - RDC - 306/2004 - ANVISA.

O plano de gerenciamento de resíduos de serviços de saúde do Hospital X foi elaborado por um grupo de trabalho composto pelo SESMT que também possui sua responsabilidade técnica de implantação. No mesmo encontram-se os resíduos separados pela sua classe e áreas de localização com características e afins.

\section{RESULTADOS E DISCUSSÃO}

Persp. online: exatas \& eng., Campos dos Goytacazes, 3 (6), 56-72, 2013 
Compreendendo que a Logística Reversa considera tópicos como redução, conservação da fonte, reciclagem, substituição e descarte, após verificação do conteúdo e coleta de dados no Hospital X, foi possível identificar meios de aplicar os conceitos de Logística Reversa como nova alternativa de gestão para determinados materiais.

A APIC (1992, apud CONFORTIN, 2001) relata que o método mais efetivo de gerenciar os resíduos sólidos de saúde é reduzir o volume gerado e estabelecer um programa de reciclagem com aquisição de produtos que possam ser eficientemente reciclados.

Com base no que foi observado no Hospital, foi possível identificar que os resíduos gerados são os das classes A, B, D e E, conforme as Figuras 1, 2, 3 e 4 respectivamente, (visto que o hospital não possui resíduos do grupo $\mathrm{C}$ ).

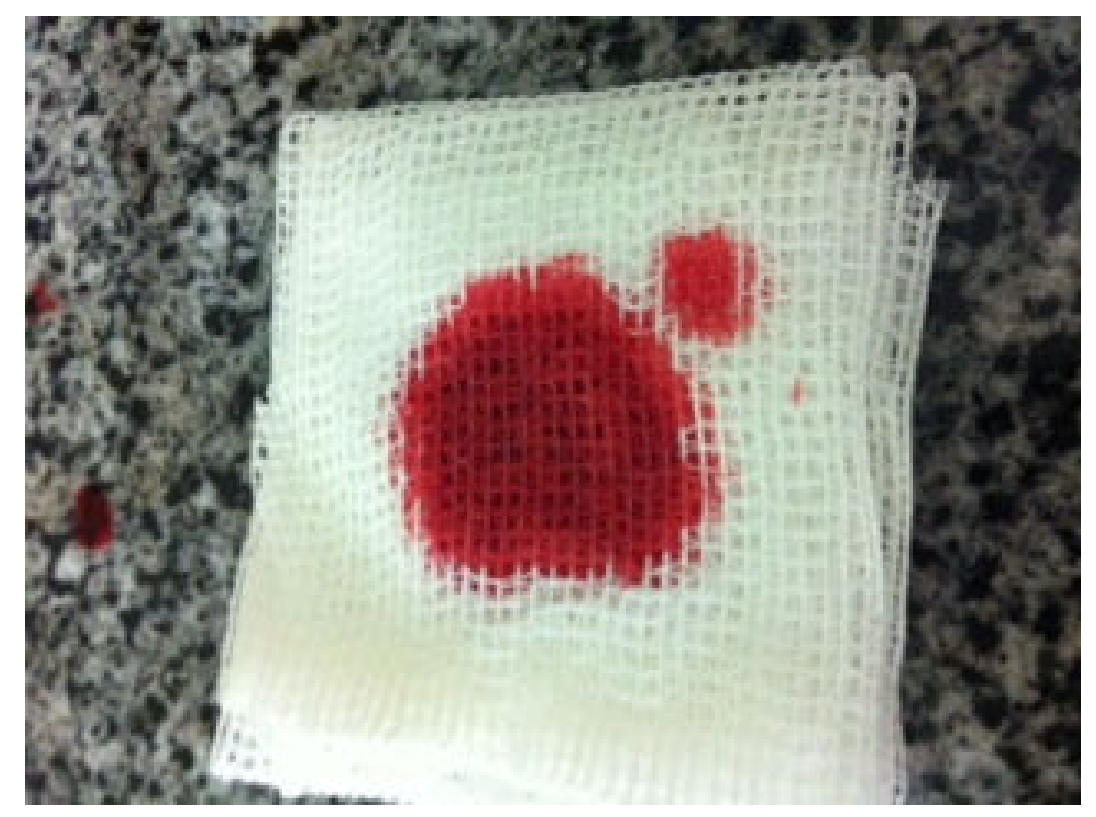

Figura 1: Resíduo de Classe A - Gase com sangue Fonte: Elaboração própria, 2012

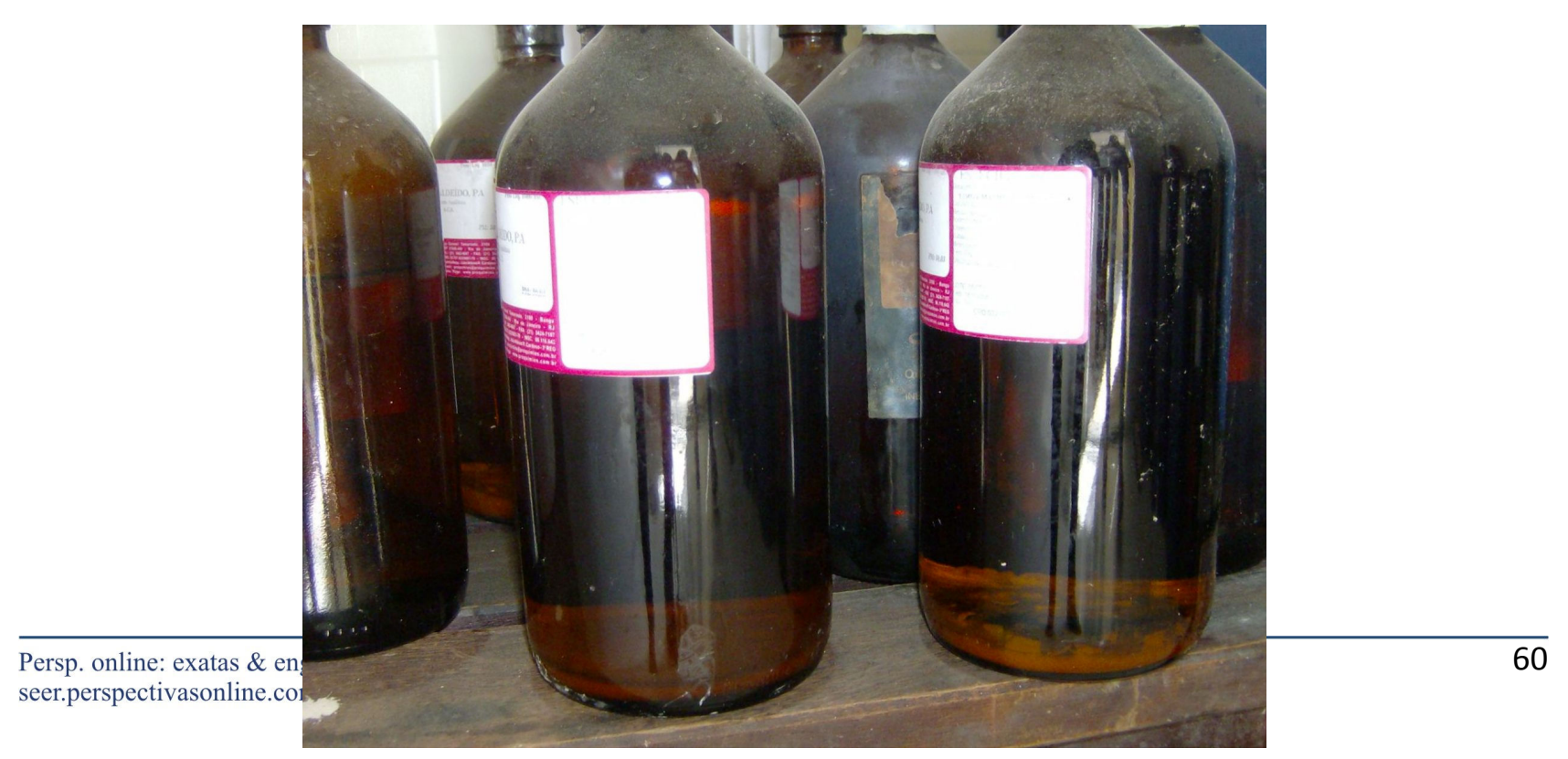


Figura 2: Resíduo de Classe B - Produto químico

Fonte: Elaboração própria, 2012.

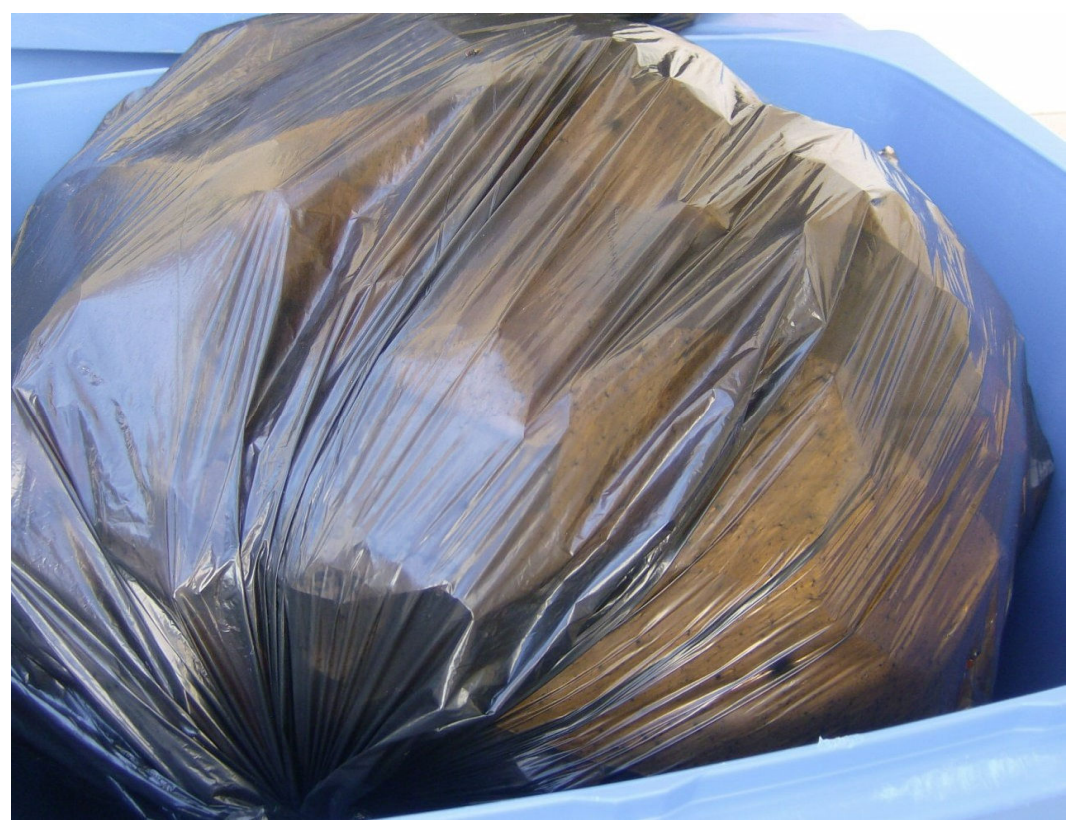

Figura 3: Resíduos de Classe D - Resíduos de varrição Fonte: Elaboração própria, 2012.

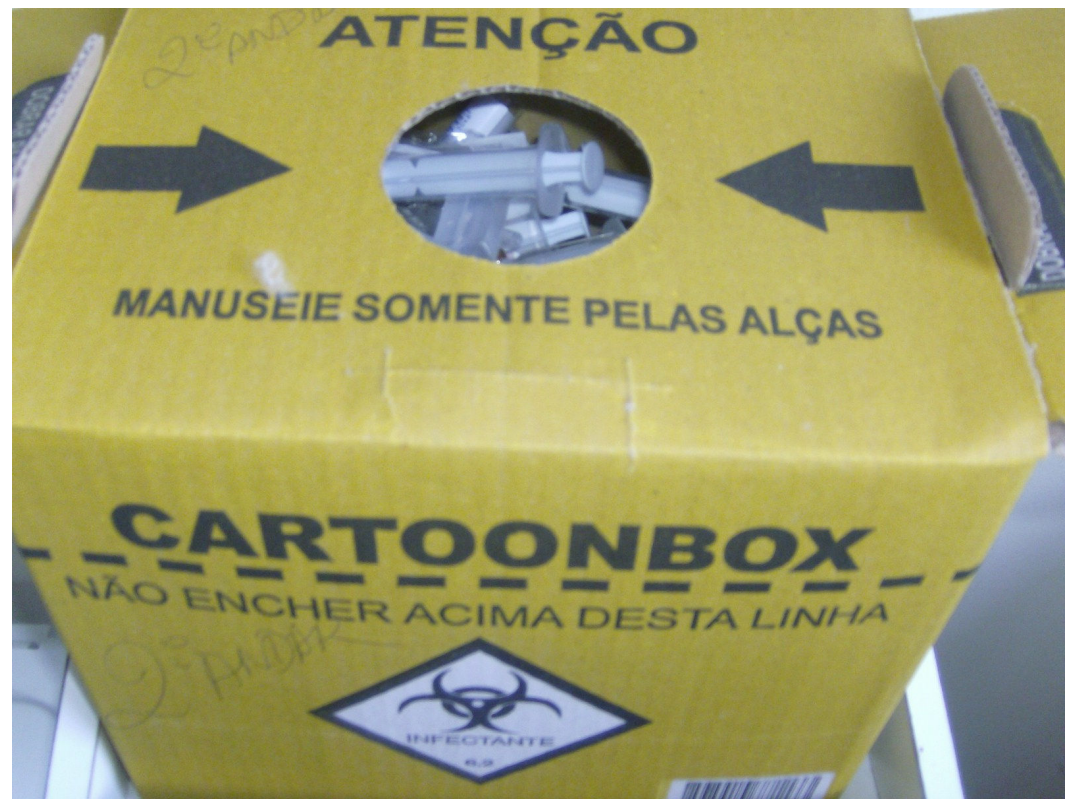

Persp. online: exatas \& eng., Campos dos Goytacazes, 3 (6), 56-72, 2013 
Figura 4: Resíduos de Classe E - Resíduos Perfuro Cortantes

Fonte: Elaboração própria, 2012.

\subsection{Alternativas de Logística Reversa como nova técnica de gestão}

Devido às suas características biológicas, químicas e físicas, os resíduos das classes $\mathrm{A}, \mathrm{B}$ e $\mathrm{E}$ não podem ser reciclados ou reutilizados, devendo então ser descartados segundo consta no Plano de Gerenciamento do hospital. Os de grupo A são destinados para vala séptica e incineração, os de grupo B são enviados para reciclagem e aterro, os de grupo $\mathrm{D}$ (os que não são passíveis de reutilização) são enviados para aterro e os de grupo E são destinados para a vala séptica.

Após a caracterização dos resíduos, percebeu-se que somente os pertencentes a Classe D são passíveis de reutilização, já que não apresentam características de riscos biológicos, físicos, químicos ou radiológicos, tanto para saúde como para o meio ambiente. De fato, os resíduos da classe D podem ser equiparados com os domiciliares, ou seja, orgânicos, resíduos provenientes de áreas administrativas, óleo de cozinha, equipos de soro, papel absorvente e fraldas descartáveis.

A seguir, caracterizam-se os resíduos hospitalares que foram passíveis de aplicação da Logística Reversa, não somente em seu descarte adequado, mas também ao seu possível retorno ao próprio processo produtivo:

\section{a) Resíduos não recicláveis:}

Os resíduos não recicláveis são materiais que por alguma limitação em sua composição ou pela dificuldade de processamento não são viáveis para a reciclagem. Essa limitação pode ser consequência da sua composição, ou ainda dificuldades na comercialização e/ou no processo de reciclagem propriamente dito. Por isso, esses resíduos são encaminhados a aterros sanitários.

No Hospital X, esses resíduos não recicláveis são provenientes de áreas como a cozinha, refeitório, banheiros, áreas administrativas, entre outras, conforme a Figura 5.

Exemplos de materiais não recicláveis são: tecidos, lâmpadas incandescentes, espelhos, vidros que contenham tela metálica, embalagens sujas, papéis "contaminados" (papéis sanitários, plastificados, metalizados, parafinados, papel carbono, fotografias, papel vegetal, termossensíveis - como fax e extrato bancário, guardanapos e lenços de papel, fitas e etiquetas adesivas), plásticos termofixos (telhas transparentes, proteções para telefones públicos), plástico filme, madeira, esponja de aço, materiais orgânicos, embalagens aluminizadas (algumas embalagens de biscoitos, chocolates, barrinhas de cereal etc.), fraldas e absorventes descartáveis, utensílios de cerâmica e porcelana e espumas (MANSOR; MEIRA et al, 2010 apud NADAI, 2012). 


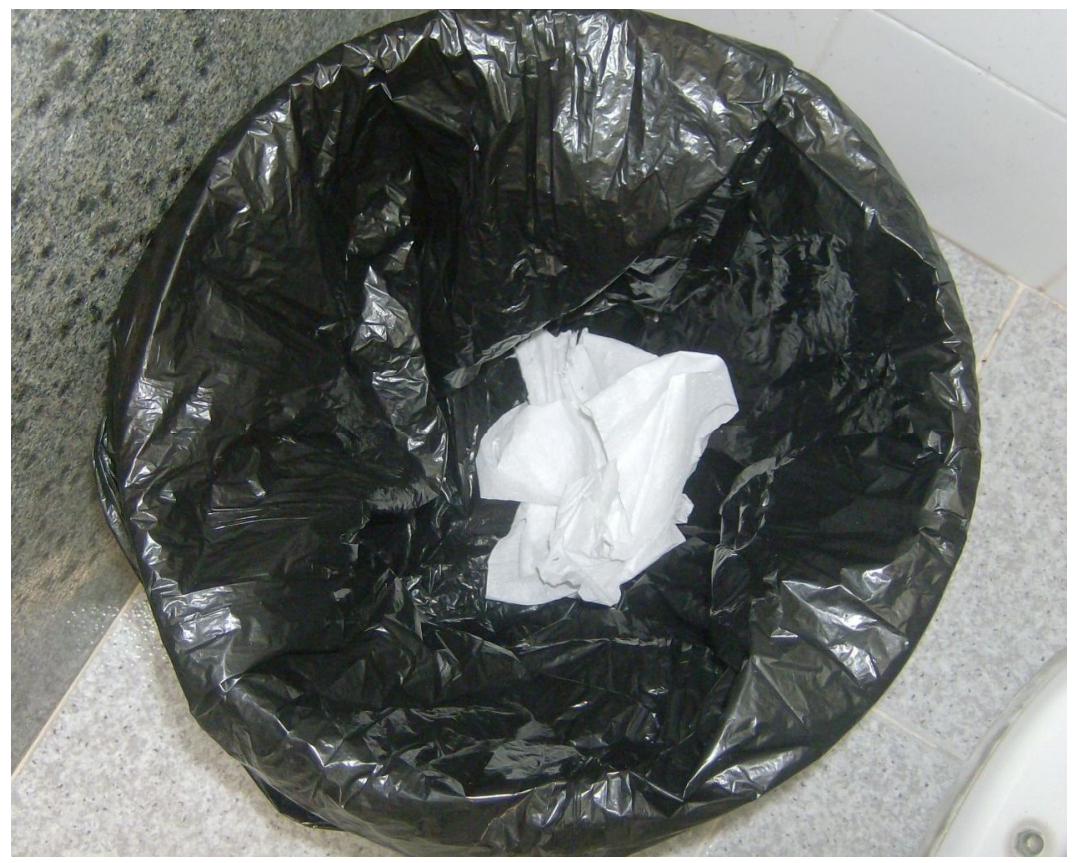

Figura 5: Resíduos não recicláveis - Papel sanitário Fonte: Elaboração própria, 2012.

\section{b) Resíduos Orgânicos:}

Tem como principal característica sua biodegradabilidade. Esses resíduos possuem elevados teores de nutrientes e umidade que, associados a temperaturas favoráveis, promovem o desenvolvimento de microorganismos decompositores. Estes resíduos apresentam grande potencial de produção de condicionadores de solo. Os compostos orgânicos, portanto, desde que isentos de restos inorgânicos, podem ser incorporados ao solo das áreas de jardinagem do hospital como adubo, depois que passarem pelo processo de trituração. São eles: resíduos de varrição, flores, podas e jardins; resto alimentar de refeitório; resto alimentar de paciente, representado na Figura 6.

Com o aumento dos custos de energia e de fertilizantes, alguns resíduos orgânicos têm sido novamente considerados como fontes potenciais de nutrientes para o crescimento de plantas e para a melhoria das propriedades do solo (ELLIOTT \& STEVENSON, 1977 apud ANDRADE et al. 2006) dependências.

Esses resíduos orgânicos, no Hospital $\mathrm{X}$, são provenientes de pátio, cozinha, refeitórios e

Dentre os resíduos orgânicos gerados, ainda pode-se destacar as sobras de preparos de alimentos (como as cascas de verduras e legumes, por exemplo) que, por não terem tido contato com o ambiente fora 
da cozinha do hospital, poderão ser reaproveitados para o preparo de outras refeições, identificando assim mais uma possibilidade da aplicação da Logística Reversa.

Com o aproveitamento integral dos alimentos é possível reduzir o custo das preparações, contribuir para a diminuição do desperdício alimentar, aumentar o valor nutricional e tornar possível a elaboração de novas preparações (GONDIM et al. 2005, apud NUNES e BOTELHO, 2009).

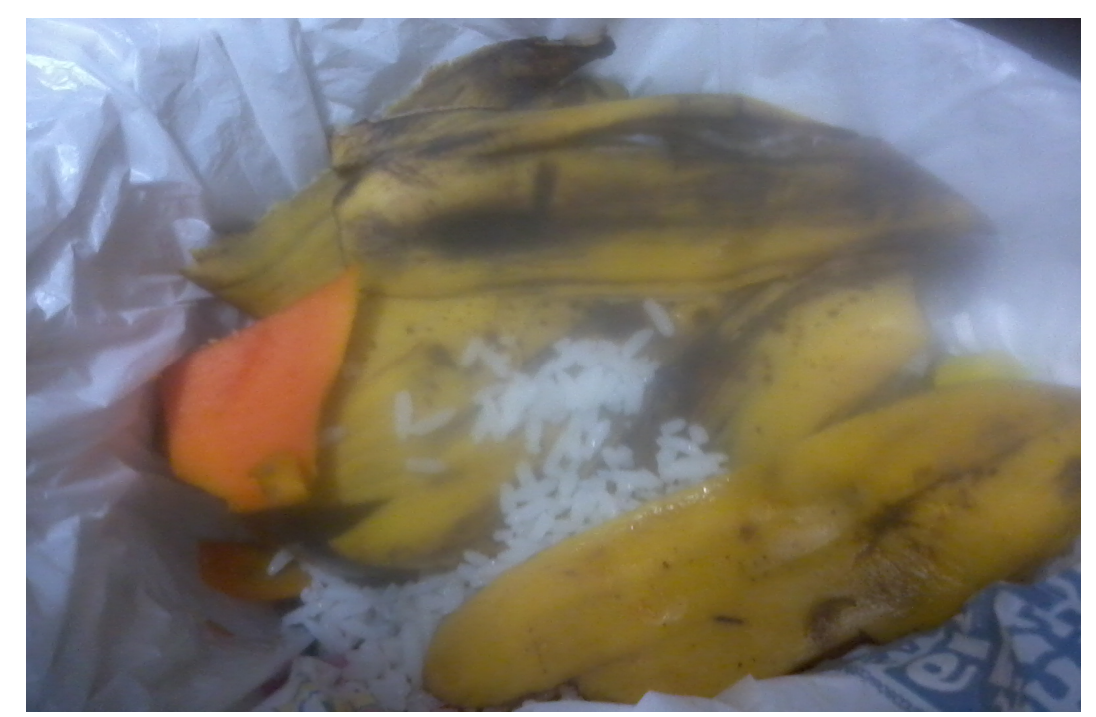

Figura 6: Resíduos Orgânicos - Cascas de verduras e alimentos Fonte: Elaboração Própria, 2012.

\section{c) Óleo de Cozinha:}

Existe hoje uma preocupação relacionada ao meio ambiente e a esta eminente elevação no consumo do óleo de cozinha, que vem sendo usado em frituras, cujo consumo excessivo causa malefícios ao organismo e danifica o meio ambiente se descartado incorretamente, como pelo ralo da pia, já que provocará entupimento das tubulações da rede de esgoto, aumentando custos de tratamento de água, e contaminação dos rios e mares (RABELO e FERREIRA, 2008).

Somente agora os ambientalistas admitem que não há um modelo de descarte ideal para os resíduos graxos, mas sim alternativas como a fabricação de biodiesel e sabão (RABELO e FERREIRA, 2008).

Esse óleo gerado é proveniente do preparo dos alimentos para os pacientes.

Assim sendo, o óleo gerado deve ser armazenado em recipientes com tampa, conforme a Figura 7 e identificados quanto à sua quantidade, procedência e gerador, para ser encaminhados à produção de sabão e detergentes (havendo parceria com empresas produtoras) que possam ser consumidos pelo hospital. 


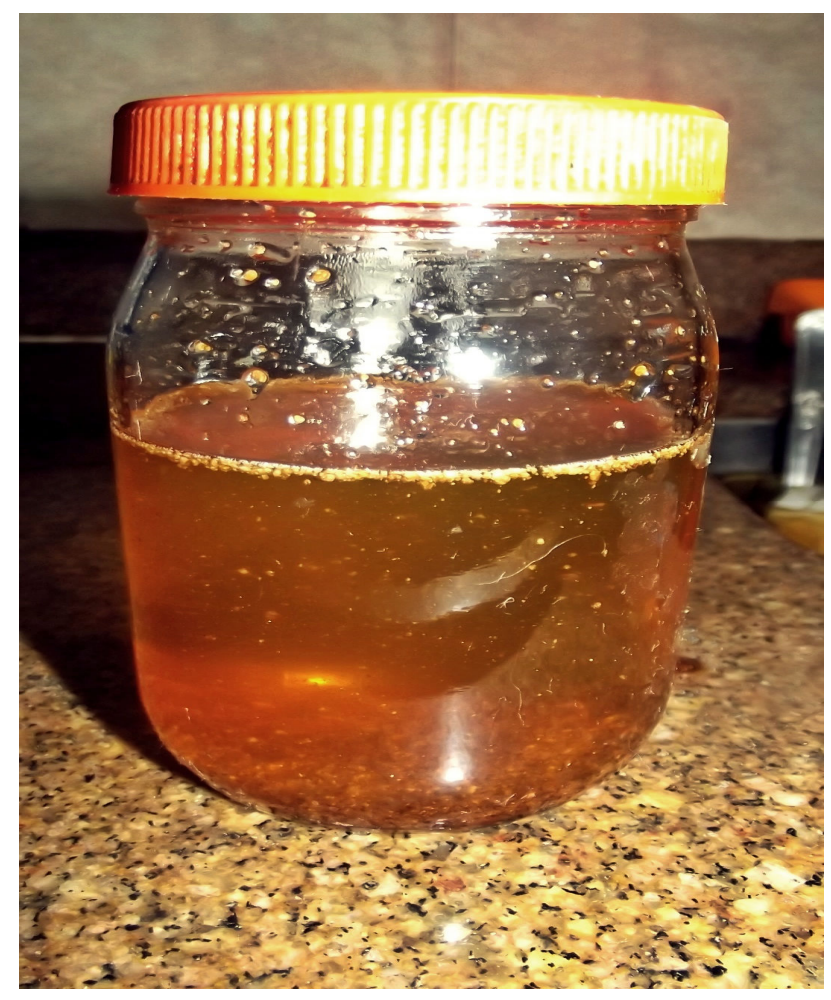

Figura 7: Imagem ilustrativa do óleo de cozinha usado Fonte: Elaboração Própria, 2012.

\section{d) Equipo de Soro e frasco:}

Os equipos de soro são artigos descartáveis, indicado para uso profissional médico hospitalar, como acessório encaixado no scalp ou agulha que está no paciente. Com a finalidade de aplicar soluções e soro, possibilita a locomoção e os movimentos sem precisar interromper a aplicação do soro no paciente, já o frasco é o local onde o soro fica armazenado, conforme a Figura 8.

No Hospital X, esses equipos podem ser encontrados nas enfermarias, ambulatórios e na unidade de tratamento intensivo.

Nem todos os equipos de soro podem ser reciclados, pois há os oriundos de unidades de isolamento, os que foram contaminados com sangue, ou que foram utilizados para infundir medicamentos que 
apresentem risco ambiental ou sanitário. Se o material não possuir as características anteriores, o equipo e o frasco de soro podem ser reciclados.

No tocante à Logística Reversa, esse plástico caracterizado como comum, pode ser reciclado para voltar ao Hospital como sacolas de lixo, baldes, cabides, recipientes, entre outros artigos.

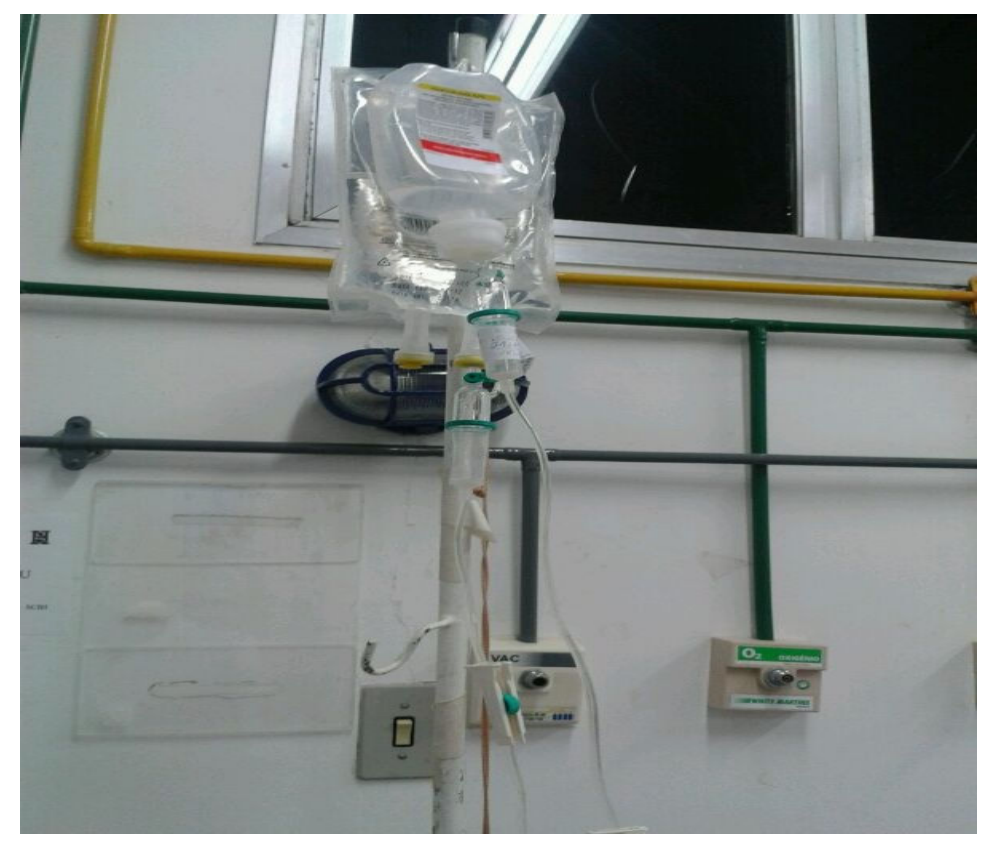

Figura 8: Figura ilustrativa do Equipo de Soro e Frasco

Fonte: Elaboração Própria, 2012

\section{e) Resíduos provenientes das áreas administrativas/consultas externas:}

As áreas administrativas e salas de consultas externas do hospital geram diversos resíduos e estes por sua vez podem ser reciclados. Para isto, devem ser separados de acordo com suas características físicas.

Papel, papelão, envelopes de papel, copos descartáveis, envelopes de plástico, galões de plástico, carcaças e tampas de caneta, capas de proteção de agulhas, dentre outros materiais, são resíduos gerados no hospital que, devido à sua natureza, podem ser reutilizados ou transformados em matéria-prima para fabricação de novos produtos.

Dentre esses resíduos gerados, o que pode ser visto em maior quantidade pelo Hospital X é o papelão, tendo uma sala separada só para ele, conforme a figura 9.

Com isso, esse papelão poderá ser enviado para a reciclagem e assim ser transformado em novos produtos, como por exemplo, sacolas, agendas, materiais para a área administrativa a serem adquiridos pelo hospital. 


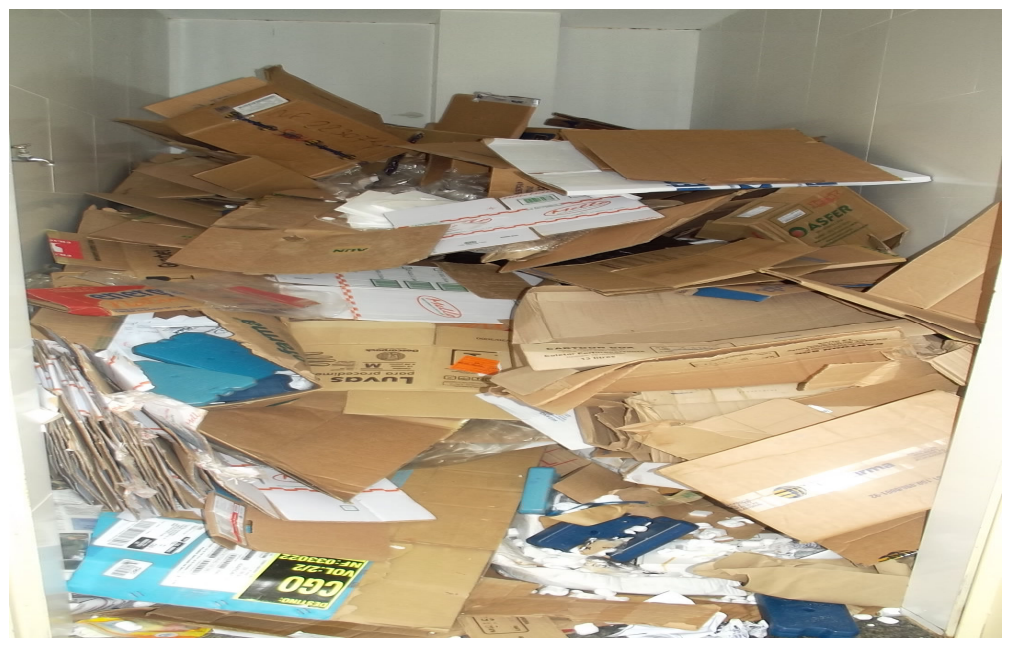

Figura 9: Resíduos provenientes de áreas administrativas Fonte: Elaboração própria, 2012.

Ainda neste trabalho, obtiveram-se como resultados questões que foram levantadas através das entrevistas, aplicadas a dois responsáveis pelo PGRSS, e o que pôde ser observado no estudo de campo.

Ao ser levantada a questão se a empresa coletora terceirizada possui licenciamento ambiental para fazer a coleta dos resíduos gerados pelo hospital, ambos os entrevistados (Técnico em Segurança do Trabalho e o Engenheiro de Segurança do Trabalho) afirmaram que a Empresa possui licenciamento para tal atividade, e que este documento está com seu prazo de validade em dia. Segundo a (RDC) ANVISA $n^{\circ}$ 306/04, compete aos serviços geradores de RSS:

[...] requerer às empresas prestadoras de serviços terceirizados a apresentação de licença ambiental para o tratamento ou disposição final dos resíduos de serviços de saúde, e documento de cadastro emitido pelo órgão responsável de limpeza urbana para a coleta e o transporte dos resíduos.

Uma questão relevante e positiva que se obteve é a conscientização por parte dos membros do Hospital da importância que o plano de gerenciamento de resíduos representa para o meio ambiente, principalmente quando considerada a minimização dos impactos negativos, não sendo feito apenas para cumprir exigências legais. 
De acordo com a enfermeira e professora Mirelli Silotti (terceira entrevistada), no hospital onde atua, uma dificuldade encontrada é a conscientização de toda a equipe na segregação adequada do resíduo.

Para Corrêa (2005), os problemas com os resíduos sólidos são cada vez mais perceptíveis e progressivos e que contribui para a degradação dos recursos hídricos, do solo e dor ar, e grande volume desses resíduos gerados e mal gerenciados contribui para degradação do ambiente e uma pior qualidade de vida.

Nesta perspectiva, pontos contraditórios foram identificados durante a pesquisa, entre o que consta no PGRSS do Hospital e o que foi observado, tendo em vista que os responsáveis pelo plano afirmam seguir a RDC 306/04.

Um exemplo claro é que o Hospital possui um abrigo externo, mas que não segue na íntegra o que manda essa resolução.

Como pode ser visto nas Figuras 10 e 11, a sala não possui as canaletas de escoamento de águas como afirma ser necessário a RDC ANVISA n 306/04:

O abrigo referido neste regulamento deve ter porta provida de tela de proteção contra roedores e vetores, de largura compatível com as dimensões dos recipientes de coleta externa, pontos de iluminação e de água, tomada elétrica, canaletas de escoamento de águas servidas direcionadas para a rede de esgoto do estabelecimento e ralo sifonado com tampa que permita a sua vedação.

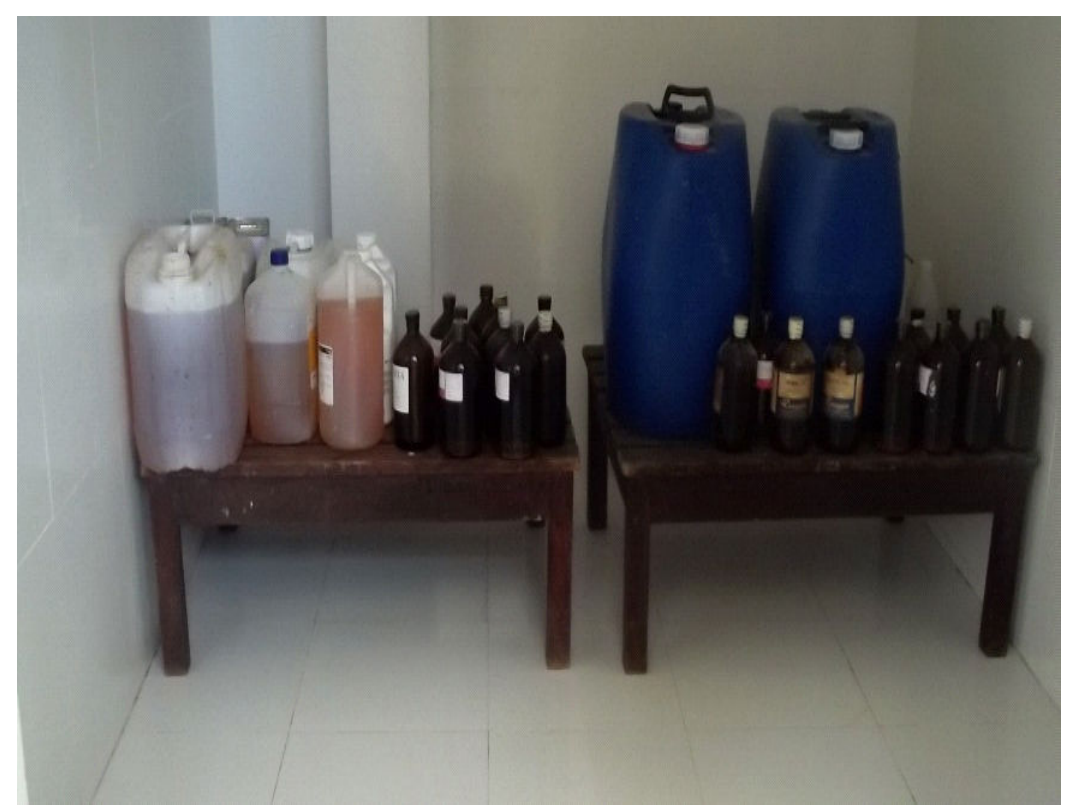

Figura 10: Abrigo externo de resíduos de Classe B, sem canaleta Fonte: Elaboração própria, 2012. 


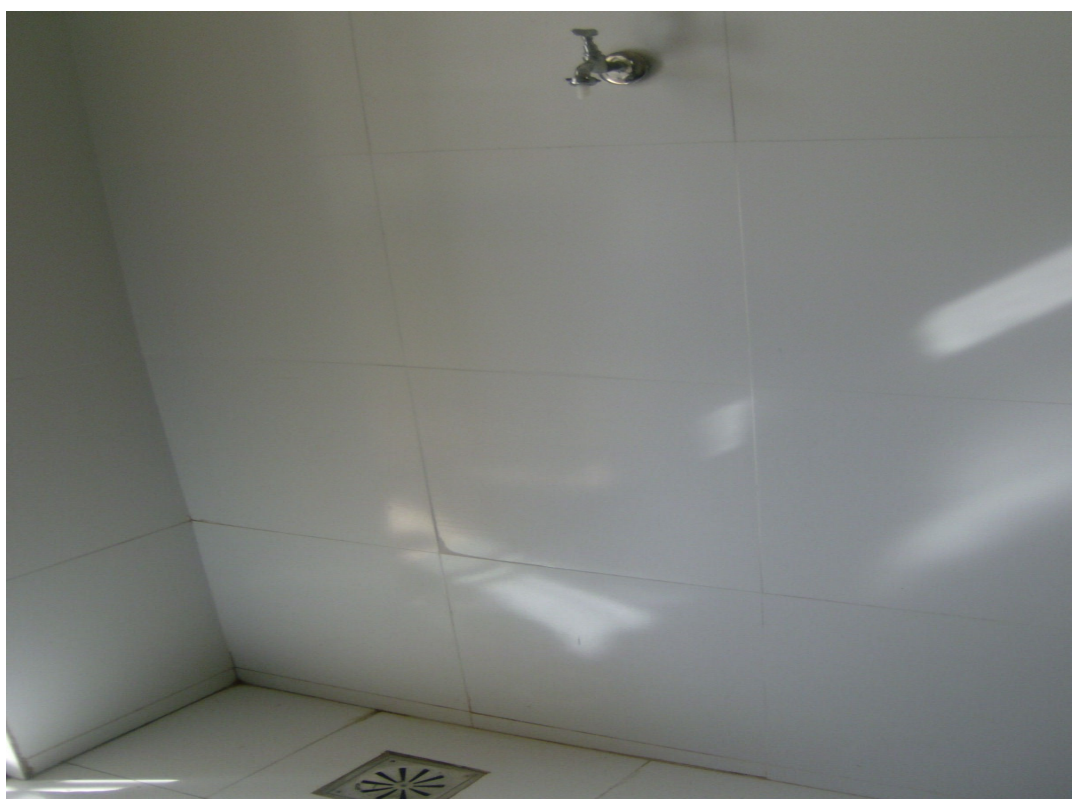

Figura 11: Ambiente com torneira e ralo. Fonte: Elaboração própria, 2012.

Outra questão contraditória corresponde às respostas quanto à desinfecção, antes do descarte, das agulhas utilizadas nos procedimentos. O primeiro entrevistado (Técnico em Segurança do Trabalho) afirmou que essa desinfecção ocorre como descrito no Plano. O segundo (Engenheiro de Segurança do Trabalho) afirmou que não ocorre, sendo responsabilidade do hospital somente enviar tudo à empresa coletora, visto que seria necessária uma estrutura específica e, se esse trabalho fosse realizado pelos funcionários, poderia ocorrer um grande número acidentes de trabalho. Já o que consta no plano é que: "os resíduos biológicos infectantes e perfuro cortantes são submetidos a um tratamento de desinfecção térmica (autoclavagem, e, posteriormente, recolhidos diariamente por uma empresa terceirizada)".

Segundo consta na RDC n ${ }^{\circ} 306$, de 07 de dezembro de 2004:

Os resíduos perfuro cortantes contaminados com agente biológico, microrganismos com relevância epidemiológica e risco de disseminação ou causador de doença emergente que se torne epidemiologicamente importante ou cujo mecanismo de transmissão seja desconhecido, devem ser submetidos a tratamento, utilizando-se processo físico ou outros processos que vierem a ser validados para a obtenção de redução ou eliminação da carga microbiana.

Por experiência, a Enfermeira e professora Mirelli informa que uma das maiores ocorrências de acidentes de trabalho se dá com perfuro cortantes contaminados e com respingo de mucosa, que por sua vez podem causar ao ser humano transmissão de HIV, hepatite $\mathrm{B}$, hepatite $\mathrm{C}$ e também risco de contaminação do meio ambiente.

No que condiz à identificação para o reconhecimento dos resíduos, foi observado que apesar de seguir a norma em relação à presença de simbologia em sacos e recipientes, essa se encontrava de maneira errônea por apresentar cor discrepante do que é correto, como ilustra a Figura 12. Conforme consta na NBR7500 da ABNT, os resíduos do grupo A devem ser identificados pelo símbolo de substância infectante, com rótulos de fundo branco, desenho e contornos pretos. 


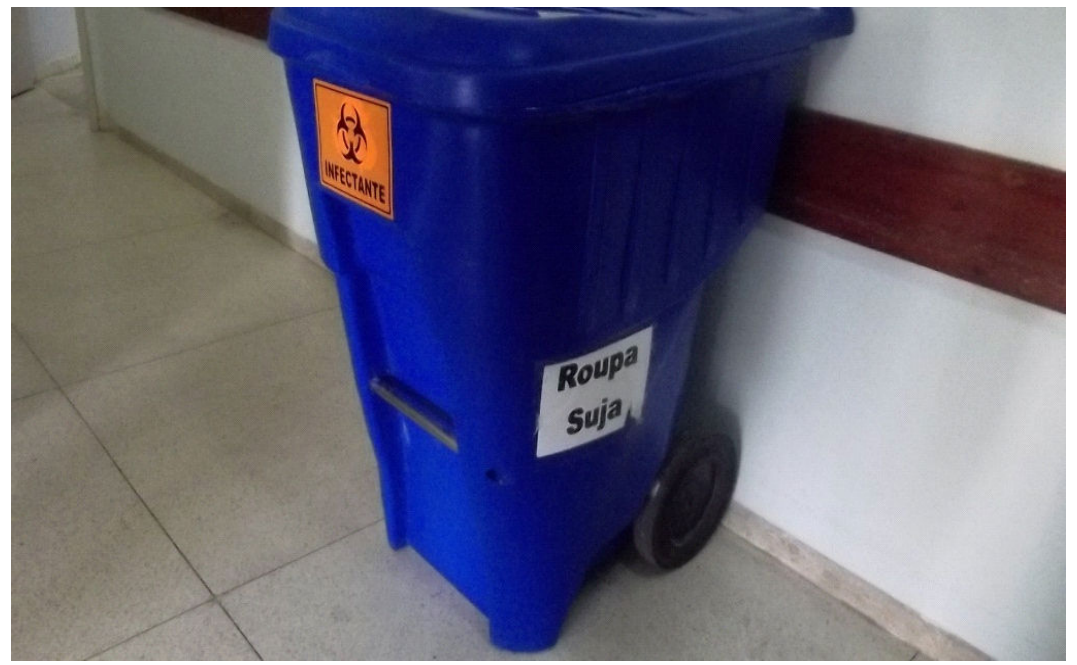

Figura 12: Recipiente com erro de identificação Fonte: Elaboração própria, 2012.

\section{CONCLUSÕES}

Ao analisar o que é proposto pelo Plano de Gerenciamento e o que de fato é colocado em prática no Hospital X, foi possível identificar algumas inconformidades já que o plano segue as normas da (RDC) ANVISA 306/04.

Com base nas informações coletadas, foi verificado que o Hospital X gera resíduos das classes A (apresentam riscos potenciais à saúde por características biológicas), B (apresentam riscos potenciais à saúde por características químicas), D (não apresentam riscos, são equiparados aos domiciliares) e E (perfuro cortantes ou escarificantes), tendo em vista que o hospital não possui resíduos da classe $\mathrm{C}$, que são radioativos.

Percebeu-se que os resíduos são gerenciados conforme suas classes, sendo manuseados, transportados e acondicionados de acordo com suas características químicas, físicas e biológicas. $\mathrm{O}$ gerenciamento é realizado pela equipe técnica, sob orientação e supervisão do SESMT, dependendo das características dos rejeitos existentes e de suas áreas geradoras.

Ainda de acordo com o que consta no PGRSS do Hospital X, os resíduos de classe A são destinados de duas formas dependendo de suas características, sendo assim encaminhados para valas sépticas e incineração. Os resíduos de classe B têm como destinação os aterros, exceto alguns medicamentos específicos que são devolvidos aos fabricantes. Os resíduos de classe $\mathrm{D}$, também são encaminhados para aterros, e por ultimo, os resíduos de classe E são encaminhados para valas sépticas.

Portanto, no decorrer do trabalho, que teve como principal foco meios possíveis de utilização da Logística Reversa para o gerenciamento dos resíduos de serviços de saúde, foi constatado que para os grupos de resíduos de classe $\mathrm{A}, \mathrm{B}$ e $\mathrm{E}$ (devido suas características infecciosas, patogênicas ou que ofereçam algum risco à saúde) torna-se inviável a aplicação de todos os conceitos da Logística Reversa. Assim sendo, torna- 
se possível a aplicação da Logística Reversa, quanto ao retorno dos insumos ao ciclo produtivo, à resíduos pertencentes à classe $\mathrm{D}$, uma vez que estes não são prejudiciais à saúde da população e ao meio ambiente, podendo ser enviados à reciclagem, transformados em novos produtos, retornando então ao hospital ou enviados à outros processos produtivos.

O presente estudo demonstra que muitas vezes os impactos negativos causados ao meio ambiente, por parte dos resíduos, devem-se à utilização de forma incompleta, ineficiente e ineficaz dos produtos e isto, conseqüentemente, acarreta custos extras às organizações, como de manuseio, armazenamento e descarte.

\section{REFERÊNCIAS BIBLIOGRÁFICAS}

ABNT - ASSOCIAÇÃO BRASILEIRA DE NORMAS TECNICAS. Identificação para o transporte terrestre, manuseio, movimentação e armazenamento de produtos. NBR 7500-. Rio de Janeiro, 2011.

ABNT - ASSOCIAÇÃO BRASILEIRA DE NORMAS TECNICAS. Resíduos Sólidos- Utilização de Resíduos Sólidos - Classificação. NBR 10004 -. Rio de Janeiro, 2004.

AGÊNCIA NACIONAL DE VIGILÂNCIA SANITÁRIA - ANVISA. RDC n. 306, de 7 de dezembro de 2004. Dispõe sobre o regulamento técnico para o gerenciamento dos Resíduos dos Serviços de Saúde.

ANDRADe, G. C.; Bellote, A. F. J.; SILVA, H. D.; Acúmulo de Nutrientes na Biomassa e na Serrapilheira de Eucalyptus grandis em Função da Aplicação de Lixo Urbano e de Nutrientes Minerais. 2006. 135p.

BARBIERI, J. C.; DIAS, M.; Logística reversa como instrumento de programas de produção e consumo sustentáveis. Tecnologística. São Paulo, n. 77, p. 58-69, 2002.

BRASIL, Constituição Federal. VI - Do Meio Ambiente (ART 225). Disponível em: $<$ http://alerjln1.alerj.rj.gov.br/constfed.nsf/16adba33b2e5149e032568f60071600f/62e3ee4d23ca92ca032 5656200708dde?OpenDocument> Acesso em: 5 ago. 2012.

BRASIL, Ministério da Saúde. Agência Nacional de Vigilância Sanitária. Manual de gerenciamento de resíduos de serviços de saúde. Brasília: Ministério da Saúde, 2006.

CONAMA. Resolução CONAMA nº 283. Brasília, 12 jul. 2001.

CONAMA. Resolução CONAMA n 358. Brasília, 29 abr. 2005.

CLM - COUNCIL OF LOGISTICS MANAGMENT. Disponível em: $<$ http://www.schiefer.com.br/logistica/corpo_logistica.htm>. Acesso: 05 jun. 2007.

CONFORTIN, A. C. Estudo dos Resíduos de Serviços de Saúde do Hospital Regional do Oeste/SC. 2011. 181 p. Dissertação (Mestrado) - Universidade Federal de Santa Catarina - UFSC, Florianópolis, 2011.

GUIA PRÁTICO PARA MINIMIZAÇÃo E GERENCIAMENTO DE RESÍDUOS - USP SÃo CARLOS. $\quad$ Disponível em $\quad<$ http://www.ifsc.usp.br/qualidade/images/stories/guia_usp_recicla_digital.pdf $>>$ Acesso: 10 nov. 2012. 
BRASIL. LEI N ${ }^{\circ}$ 12.305, de 02 de Agosto de 2010 (Institui a Política Nacional de Resíduos Sólidos; altera a Lei $\mathrm{n}^{0} 9.605$, de 12 de fevereiro de 1998; e dá outras providências) Disponível em $<<$ http://www.planalto.gov.br/ccivil_03/_ato2007-2010/2010/1ei/112305.htm >>. Acesso: 14 de jul. 2012.

BRASIL. Lei $\mathbf{N}^{0}$ 4.352, de 30 de Junho de 2009 (Dispõe sobre o tratamento e a disposição final dos resíduos dos serviços de saúde). Disponível em $<<$ http://www.crodf.org.br/stdweb/imagensCRODF/LEI.pdf $>>$ Acesso: 8 jun. 2012.

BRASIL. LEI No 4191, de 30 de Setembro de 2003 (Dispões sobre a Política Estadual de Resíduos Sólidos e dá outras providências) Disponível em $<<$ http://alerjln1.alerj.rj.gov.br/contlei.nsf/e9589b9aabd9cac8032564fe0065abb4/cf0ea9e43f8af64e83256db300 647e83?OpenDocument >> Acesso: 9 de Nov. 2012.

MINISTÉRIO DA SAÚDE. Agência Nacional de Vigilância Sanitária. Manual de gerenciamento de resíduos de serviços de saúde / Ministério da Saúde, Agência Nacional de Vigilância Sanitária. Brasília: Ministério da Saúde, 2006.

MINISTÉRIO DO MEIO AMBIENTE, (2005) Resoluções CONAMA. Disponível em: http://www.mma.gov.br/port/conama/legiabre.cfm?codlegi=281 m 20/05/2012

Acesso

NUNES, J.T.; BOTELHO, R.B.A. Aproveitamento Integral dos Alimentos: Qualidade Nutricional e Aceitabilidade das Preparações. 2009. 64p. Monografia (Especialização) - Universidade de Brasília Brasília, 2009.

PEREIRA, André Luís. Logística Reversa de Resíduos de Serviços de Saúde do Estado de Minas Gerais. 2011. 196p. Dissertação (Mestrado) - Faculdade de Ciências Econômicas, Administrativas e Contábeis de Belo Horizonte - FACE, UNIVERSIDADE FUMEC, Belo Horizonte, 2011.

PHILIPPI JR, A.; ROMÉRO, M.; BRUNA, G. Curso de Gestão Ambiental. 2.ed. São Paulo: Manole, 2004. v.1.

RABELO, R. A.; FERREIRA, O. M. Coleta Seletiva de Óleo Residual de Fritura para Aproveitamento Industrial. 2008. 21p. Universidade Católica de Goiás, Goiás, 2008. 